\title{
Analysis and Remedies for Landslides Including Vegetation: A Case Study in Lebanon
}

\author{
Ali Fawaz ${ }^{1,2, ~ *, ~ S a r a h ~ A b d u l l a h ², ~ E l i a s ~ F a r a h ², ~ F a d i ~ H a g e c h e h a d e ~}{ }^{1,2}$ \\ ${ }^{1}$ University Institute of Technology, Lebanese University, Saida, Lebanon \\ ${ }^{2}$ Doctoral School of Sciences and Technologies, Lebanese University, Beirut, Lebanon
}

\section{Email address:}

alifawaz08@hotmail.com (A. Fawaz), sarah_abdullah_91@hotmail.com (S. Abdullah), elias_farah@live.com(E. Farah), fadihagechehade@hotmail.com (F. Hagechehade)

\section{To cite this article:}

Ali Fawaz, Sarah Abdullah, Elias Farah, Fadi Hagechehade. Analysis and Remedies for Landslides Including Vegetation: A Case Study in Lebanon. American Journal of Civil Engineering. Vol. 5, No. 6, 2017, pp. 320-330. doi: 10.11648/j.ajce.20170506.12

Received: August 18, 2017; Accepted: September 19, 2017; Published: October 12, 2017

\begin{abstract}
This paper aims to study and analyze the instability of slopes, their causes and possible remedies. The studied slope is located in Lebanon, and it is regularly subjected to slope instability in the rainfall season. Based on different boreholes results for the same site, two models were modeled using Plaxis and Talren, they were both studied under the effect of water, excavation and seismic load. The results show that the water is a principle cause of slope instability, by decreasing the shear parameters of soil or by the inducing pore pressure due to running water between layers. Many remedies were applied, and their results were analyzed and studied. Soil reinforcements, nails and piles, were applied and as water content increased, the number of reinforcement needed was high. Vegetation and drainage are more efficient when it comes to water problems. Both vegetation and drainage were modeled and the number of needed reinforcement decreased significantly assuring their advantages alongside with the reduction of the remedy price and being environmental friendly.
\end{abstract}

Keywords: Soil, Slope Stability, Safety Factor, Failure Surface, Piles, Nails, Vegetation

\section{Introduction}

Stability analysis of earth slopes is one of the fundamental calculations in geotechnical engineering. Many calculation methods and remedies have been used until now. Two main approaches are applied in slope stability analysis: Deterministic method [1] and Limit Equilibrium Methods (LEM). Fellenius [2] introduced the Ordinary or Swedish method of slices in the mid-1950s. Janbu [3] and Bishop [4] presented some improvements in this method. Bishop included inter-slice normal forces, but ignored the inter-slice shear forces. Bishop's simplified method satisfies only moment equilibrium, whereas Janbu's simplified method takes into consideration only horizontal force equilibrium. The development of numerical modeling has allowed the evolution of iterative methods, such as Morgenstern and Price [5] or Spencer [6], and the implementation of these approaches into computer softwares (Geo-Slope international). Consequently, it is possible to conduct iterative calculations allowing the inclusion of both inter-slice and equilibrium equations.
Numerical simulations are used to overcome the limitations of limit equilibrium methods which include strain-displacement procedures. Several numerical methods are gaining increasing popularity in slope stability engineering due to calculation of the safety factor calculations in an efficient way $[7,8]$. The shear strength reduction technique (SSR) starts to be a very popular numerical method for slope stability. The $c-\varphi$ reduction method is based on the reduction of the cohesion (c) and the tangent of the friction angle $(\tan \varphi)$ of the soil. These parameters are reduced in steps until the soil mass fails [9, 10]. A modified shear strength reduction technique (MSSR) was developed. It is based on reducing soils' shear properties after identification of the first slip surface. The use of MSSR has some serious advantages over LEM calculation being more sensitive [9].

The Random Finite Element Method (RFEM) is an advanced probabilistic approach that combines elasto-plastic finite element analysis with random field theory generated 
using the Local Average Subdivision Method [11]. It was able to take full account of spatial correlation and local averaging, and observe their impact on the probability of failure using a parametric approach [12].

Different slope stabilization techniques can be applied and some remedies are usually used such as piles to stabilize or recover collapsed slopes $[13,14,15]$. Nails are used to improve the shear strength of soil [16, 17, 18]. Drainage trenches are used to lower the groundwater level increasing the slope stability especially during the rainfall season [19, 20]. Recently, some researches have proposed the study of the vegetation effect on the slope stability; the studies highlighted the importance of the vegetation as a solution for landslides issues [21, 22, 23, 24, 25, 26]

In this paper, we studied a slope stability model using numerical modeling. The techniques mentioned above will be considered and modeled. The soil mechanical properties of the slope are determined from the in-situ and laboratory tests. We studied the stability of an existing slope in Lebanon, which has collapsed due to an excavation during the rainfall season. Slope stability analysis is conducted by taking into account the factors affecting its stability and the resisting techniques that help maintaining its stability.

\section{Site Description}

The slope is located in Namliyeh, Mont-Lebanon, between Dahr Al Baydar and Chtoura in Lebanon. This slope is subjected to a failure during the rainfall season. Two boreholes were drilled at this location; where in-situ Standard Penetration Test SPT was performed every $1.5 \mathrm{~m}$. Soil samples were also taken from these boreholes to be tested in the laboratory. The borehole $\mathrm{N}^{\circ} 1$ shows the existence of two main layers, a marl layer from the top surface to a depth of $7 \mathrm{~m}$, and a limestone layer from the depth of $7 \mathrm{~m}$ to the end of borehole. Table 1 shows the mechanical parameters of layers of the slope as obtained by laboratory tests or by using the SPT correlations.

Table 1. Model 1 Soil Layers Mechanical Properties.

\begin{tabular}{llllll}
\hline Layer & Nature of soil & Depth $(\mathbf{m})$ & $\mathbf{E}(\mathbf{k P a})$ & $\mathbf{c}(\mathbf{k P a})$ & $\boldsymbol{\phi}\left({ }^{\mathbf{o}}\right)$ \\
\hline 1 & Marl & $0-7$ & 8500 & 31.4 & 17.5 \\
2 & Limestone & $>7$ & 200000 & 243.3 & 17.5 \\
\hline
\end{tabular}

In addition to other parameters, the volumetric unsaturated weight $\gamma_{\text {unsat }}$ is equal to $18 \mathrm{kN} / \mathrm{m}^{3}$ and poisson's ratio $v$ is set 0.3 for both layers, while the volumetric saturated weight $\gamma_{\text {sat }}$ is equal to $20 \mathrm{kN} / \mathrm{m}^{3}$ for layer 1 and $19 \mathrm{kN} / \mathrm{m}^{3}$ for layer 2 .

The borehole $\mathrm{N}^{\circ} 2$ shows the existence of four main layers, the first one is a clay layer of $5 \mathrm{~m}$ thickness, the second is a medium sand layer of $2 \mathrm{~m}$ thickness, and dense sand between $7 \mathrm{~m}$ and $12 \mathrm{~m}$ depth, and finally a limestone layer from the depth of $12 \mathrm{~m}$ to the end of borehole. Table 2 summarizes the mechanical parameters of slope's soil layers.
Table 2. Model 2 Soil Layers Mechanical Properties.

\begin{tabular}{lllllll}
\hline Layer & $\begin{array}{l}\text { Nature of } \\
\text { soil }\end{array}$ & $\begin{array}{l}\text { Depth } \\
(\mathbf{m})\end{array}$ & $\mathbf{E}(\mathbf{k P a})$ & $\mathbf{S P T}$ & $\mathbf{c}(\mathbf{k P a})$ & $\boldsymbol{\phi}\left(\mathbf{(}^{\mathbf{}}\right)$ \\
\hline 1 & Clay & $0-5$ & 5000 & 10 & 30 & 15 \\
2 & Sand & $5-7$ & 4000 & 11 & 5 & 28 \\
3 & Dense Sand & $7-12$ & 9000 & 26 & 18 & 30 \\
4 & Marlstone & $>12$ & 200000 & - & 150 & 18 \\
\hline
\end{tabular}

In addition to other parameters, the volumetric unsaturated weight $\gamma_{\text {unsat }}$ is equal to $18 \mathrm{kN} / \mathrm{m}^{3}$ and poisson's ratio $v$ is set 0.3 for all layers, while the volumetric saturated weight $\gamma_{\text {sat }}$ is equal to $20 \mathrm{kN} / \mathrm{m}^{3}$ for layers 1,2 and 3 and $19 \mathrm{kN} / \mathrm{m}^{3}$ for layer 4.

\section{Stability Analysis}

The study of slope stability is based on the c-phi reduction method. This method is based on the incremental displacements until failure, where the final step (at failure) gives an indication of the likely failure mechanism. Two models were simulated using Plaxis software.

\subsection{Initial State}

The slope is considered in its natural state, where the failure surface of the initial slope is almost planar for both models as shown in Figures 1 and 2. The slope is stable with safety factor, $\mathrm{SF}$, equals to 2.43 for model 1 and 2.31 for model 2 .

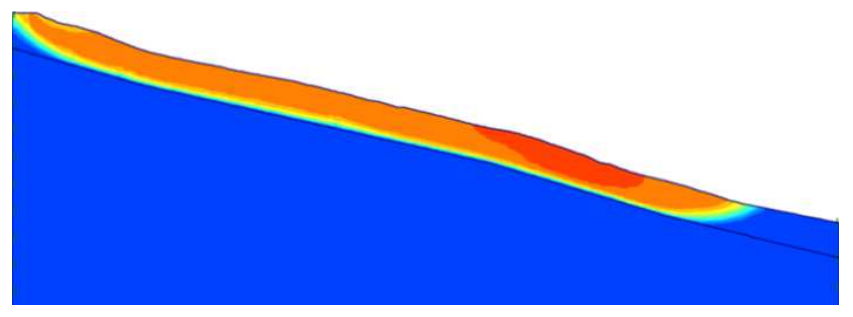

Figure 1. Failure Surface of Model 1, $S F=2.43$.

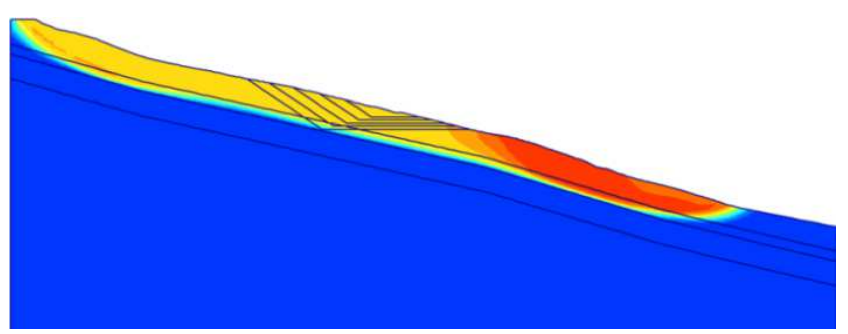

Figure 2. Failure Surface of Model 2, $S F=2.31$.

\subsection{Influence of an Excavation}

This slope is highly subjected to a manmade road excavation. The modeled road excavation can be of different widths and depths with a slope angle of $3 \mathrm{H}: 2 \mathrm{~V}$. The results for both models are shown in table 3, where the safety factor is acceptable $(\mathrm{SF}>1.5)$ in almost all cases. The slope remains stable, therefore, the excavation is not the main cause of landslide here but it might be a contributing factor. Figures 3 and 4 show the failure surface for both models which is circular due to the existence of excavation. 
Table 3. Variation of Safety Factor with Different Excavation's Depths.

\begin{tabular}{llll}
\hline Excavation & & \multicolumn{2}{l}{ Safety Factor Static } \\
\hline Width $(\mathbf{m})$ & Depth $(\mathbf{m})$ & Model 1 & Model 2 \\
\hline 0 & 0 & 2.436 & 2.306 \\
10 & 3.513 & 2.431 & 2.290 \\
15 & 5.388 & 2.400 & 2.251 \\
20 & 7.274 & 2.227 & 1.837 \\
25 & 8.831 & 2.036 & 1.514 \\
30 & 10.3 & 2.045 & 1.421 \\
\hline
\end{tabular}

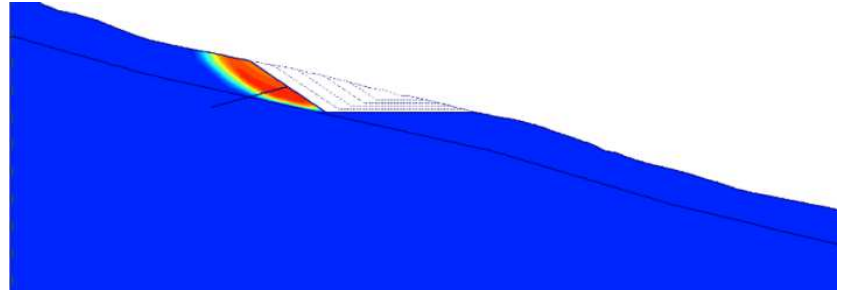

Figure 3. Failure Surface of Model 1 After 10.3 m Excavation's Depth.

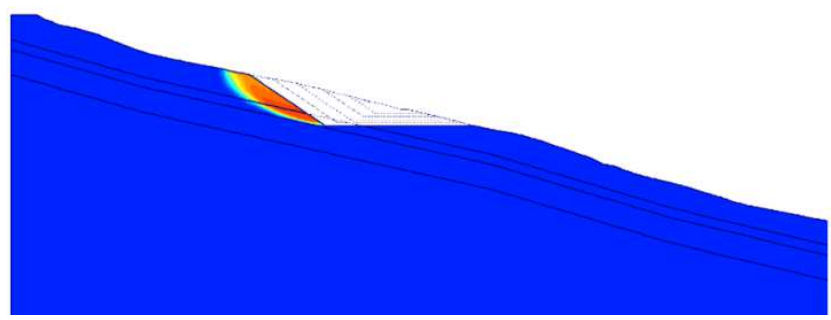

Figure 4. Failure Surface of Model 2 After 10.3 m Excavation's Depth.

\subsection{Activation of Seismic Load}

The seismic analysis is conducted by applying a seismic load with acceleration $\mathrm{a}=0.2 \mathrm{~g}$. The results for both models are shown in table 4 below, where the slope remains stable in all cases except one particular case in the $10.3 \mathrm{~m}$ excavation's depth in model 2.

Table 4. Seismic Load, Variation of Safety Factor with Different Excavation's Depths.

\begin{tabular}{lll}
\hline Excavation & \multicolumn{2}{l}{ Safety Factor Seismic } \\
\hline Depth $(\mathbf{m})$ & Model 1 & Model 2 \\
\hline 0 & 1.321 & 1.174 \\
3.513 & 1.340 & 1.182 \\
5.388 & 1.350 & 1.174 \\
7.274 & 1.303 & 1.129 \\
8.831 & 1.264 & 1.017 \\
10.3 & 1.250 & Body collapses \\
\hline
\end{tabular}

\section{Effect of Water on Slope Stability}

\subsection{Influence of Water Content on Shear Parameters}

When it rains, water falling on the surface of the soil will either infiltrate into the soil or run off along the surface. Part of the water that infiltrates into the soil will be absorbed by the upper soil layers leading to the loss of the mechanical properties of the layer.

Concerning the slope stability, it is highly affected by the increase of soil water content. Initially, the slope's water content is $15 \%$. In rainfall season, it may increase to $18 \%$, $20 \%, 22 \%$ and maybe $25 \%$. The shear strength of soil is characterized by the cohesion (c) and the friction angle $(\varphi)$. It was proven that the shear strength parameters $(\mathrm{c}, \varphi)$, for cohesive soils, decrease with the increase of moisture content $w$ [27, 28, 29]. Whereas for sand, it was shown that for granular soil with low clay quantity, the cohesion and the angle of internal friction almost do not vary with the increase of water content [30].

The figures below show the variation of the cohesion and the internal friction angle with the increase of water content of sandy clay [27].
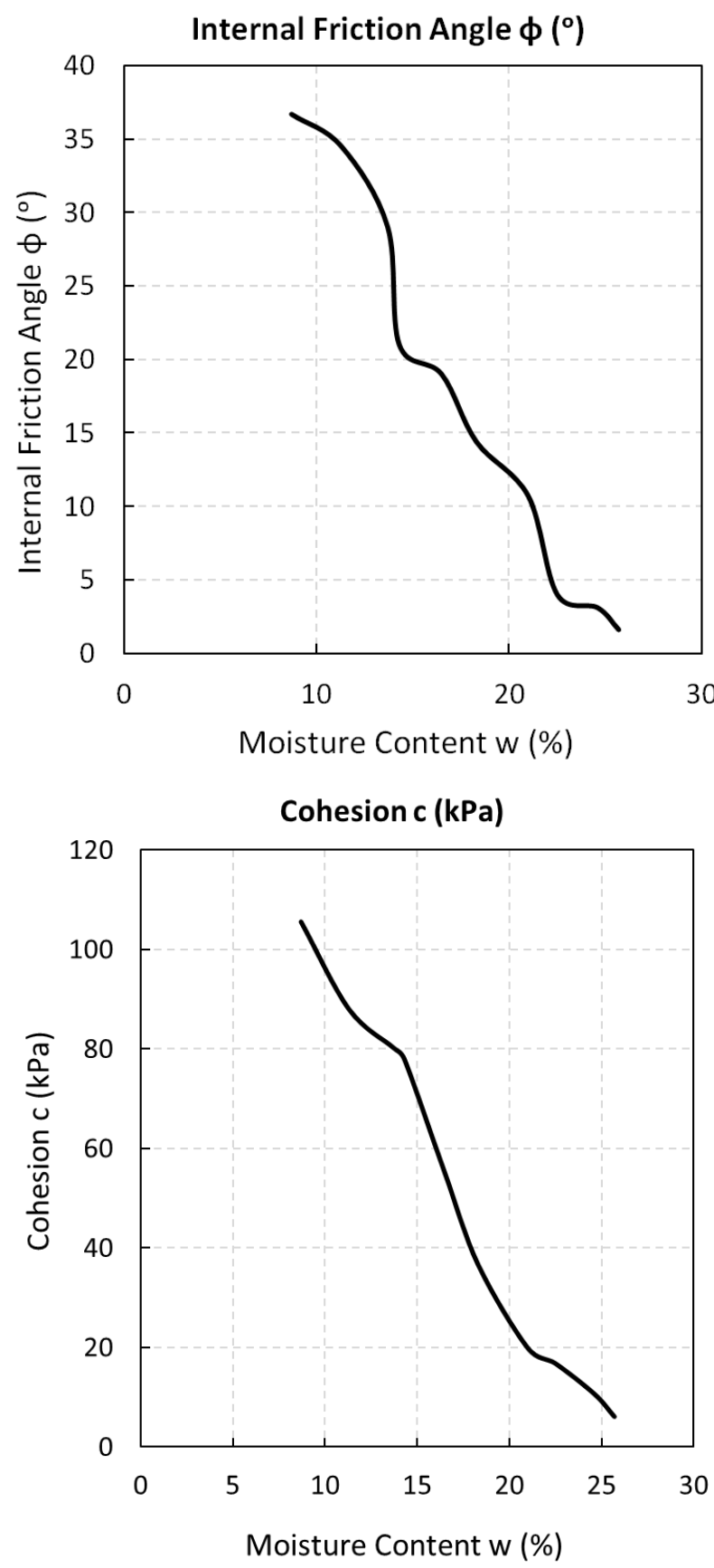

Figure 5. Variation of Shear Parameters as a Function of Moisture Content [27]. 
Table 5. Shear Parameters of Marl and Clay Based on Different Water Contents.

\begin{tabular}{lllll}
\hline Water Content & \multicolumn{2}{l}{ Marl, Model 1 } & \multicolumn{2}{l}{ Clay, Model 2 } \\
\hline $\mathbf{w ~ ( \% )}$ & $\boldsymbol{\phi ( { } ^ { \circ } )}$ & $\mathbf{c ~ ( k P a )}$ & $\boldsymbol{\phi}\left({ }^{\circ}\right)$ & $\mathbf{c ~ ( k P a )}$ \\
\hline 15 & 17.5 & 31.4 & 15 & 30 \\
18 & 13.1 & 17.4 & 11.3 & 16.6 \\
20 & 10.5 & 11.1 & 9 & 10.6 \\
22 & 5 & 7.8 & 4.3 & 7.5 \\
25 & 2.2 & 4 & 1.9 & 3.8 \\
\hline
\end{tabular}

Using the graphs shown in Figure 5, we can estimate the new shear parameters for marl (Model 1) and clay (Model 2) based on the decrease rate of cohesion and angle of internal friction with the increase of water content. The new shear parameters are shown in table 5, and figure 6 shows the variation of the safety factor as a function of water content.

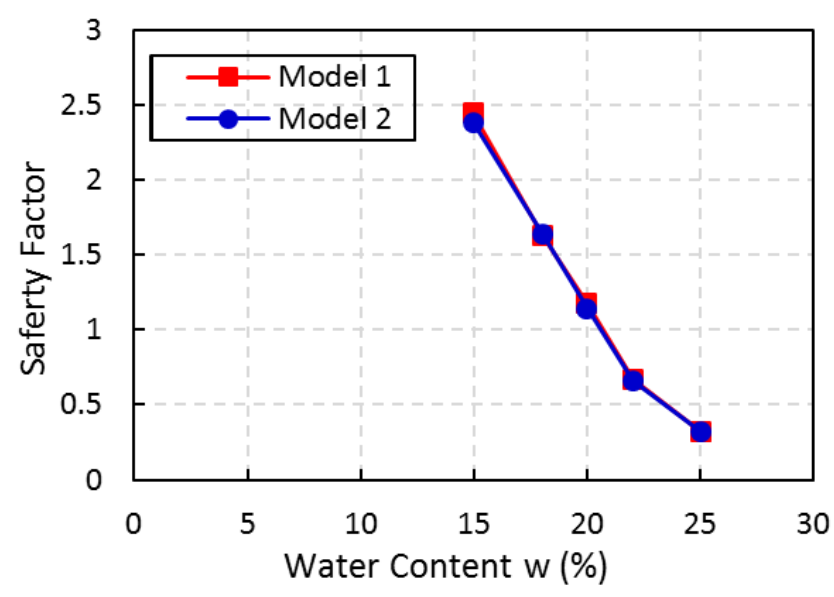

Figure 6. Variation of SF as a Function of Water Content.

Based on those results, the failure is reached $(\mathrm{SF}<1.5)$ as the water content increases reaching a value between $18 \%$ and $20 \%$.

\subsection{Influence of Excavation and Seismic Load}

The influence of an excavation and seismic loads is studied taking into account more specific cases of water content between $18 \%$ and $20 \%$. From the results of table 6 , it is obvious that the slope for $\mathrm{w}=18 \%$ is unstable in all cases after the activation of the seismic load. In the static case, when the excavation's depth increases, the safety factor decreases reaching failure. The slope for $\mathrm{w}=20 \%$ is already unstable before the application of the excavation and seismic load. The analysis of the results shows that the main cause of failure here is the increase in water content which decreases the shear parameters of marl and clay, and the application of excavation and seismic load are contributing factors in the slope instability.
Table 6. Safety Factor with Excavation and Seismic Load.

\begin{tabular}{lllll}
\hline $\mathbf{w = 1 8 \%}$ & Model 1 & & Model 2 & \\
\hline $\begin{array}{l}\text { Excavation's } \\
\text { depth (m) }\end{array}$ & SF Static & SF Seismic & SF Static & SF Seismic \\
\hline 0 & 1.568 & Failure & 1.620 & Failure \\
3.5 & 1.564 & Failure & 1.620 & Failure \\
5.4 & 1.543 & Failure & 1.482 & Failure \\
7.3 & 1.394 & Failure & 1.349 & Failure \\
8.8 & 1.267 & Failure & 1.251 & Failure \\
10.3 & 1.250 & Failure & 1.194 & Failure \\
\hline
\end{tabular}

\subsection{Influence of Running Water on Slope Stability}

The pore pressure that comes from the running water between layers can be developed due to the rising of water table or a downstream water flow.

Using Talren software, we were able to study the effect of the running water on the surface of the impermeable layer by computing the safety factor and analyzing the slope stability for both models. Different models with different pore pressures from 0 to $100 \mathrm{kPa}$ along the failure surface have been studied.

From figure 7, it is obvious that the inserted pore pressure has a great effect on the safety factor and thus the stability of the slope. For both models, static and seismic cases, the safety factor decreases about 40 to $45 \%$ with an increasing pore pressure from 0 to $100 \mathrm{kPa}$ along the failure surface between the 2 layers.

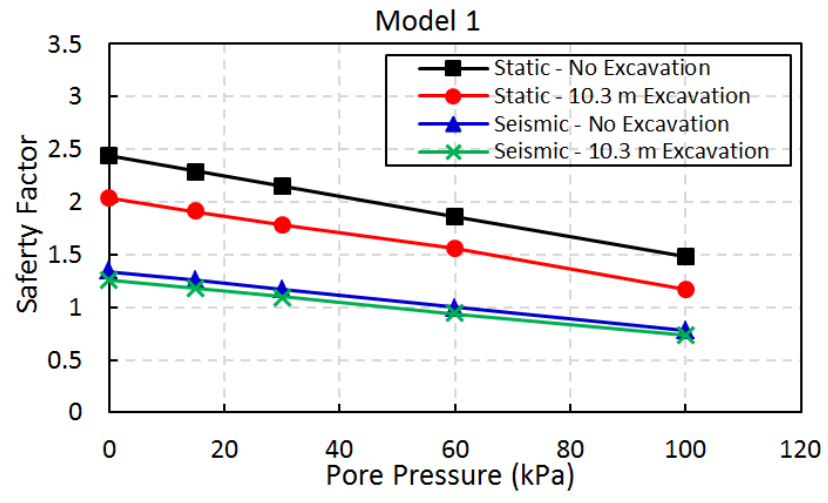

Figure 7. Model 1, Effect of Pore Pressure on Safety Factor.

\section{Remedies}

\subsection{Soil Reinforcement}

\subsubsection{Nails}

The steel nails used in this study are inclined $15^{\circ}$, spaced 2 $\mathrm{m}$ with diameter of $15 \mathrm{~cm}$, a length of $16 \mathrm{~m}$, a normal stiffness $\mathrm{EA}=1.77 \times 10^{6} \mathrm{kN} / \mathrm{m}$ and a flexural rigidity $\mathrm{EI}=2.50 \times 10^{3}$ $\mathrm{kN} . \mathrm{m}^{2} / \mathrm{m}$. Figures 8 and 11 summarize the needed number of nail rows to stabilize the slope for both models. The number of nail rows increases with the increase of both excavation's depth and water content. Figures 9, 10, 12 and 13 illustrate the location of applied nails on both models. 


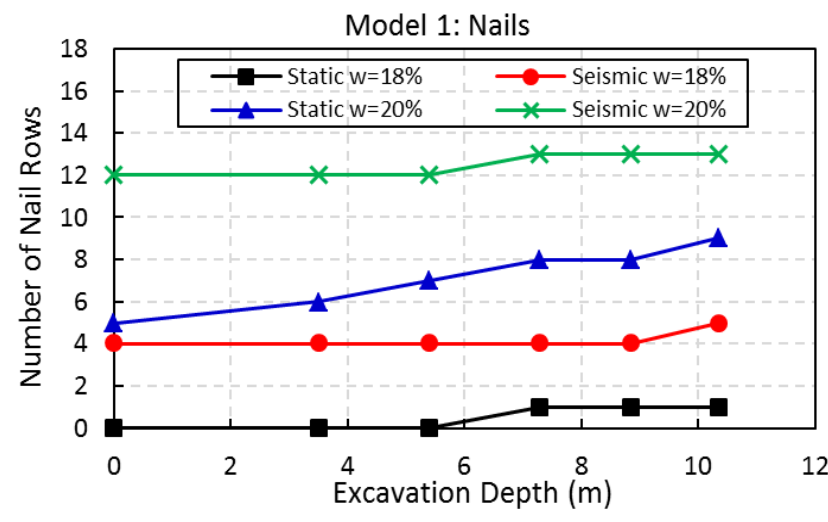

Figure 8. Model 1, Variation of Number of Nail Rows with the Variation of Excavation's Depth and Water Content.

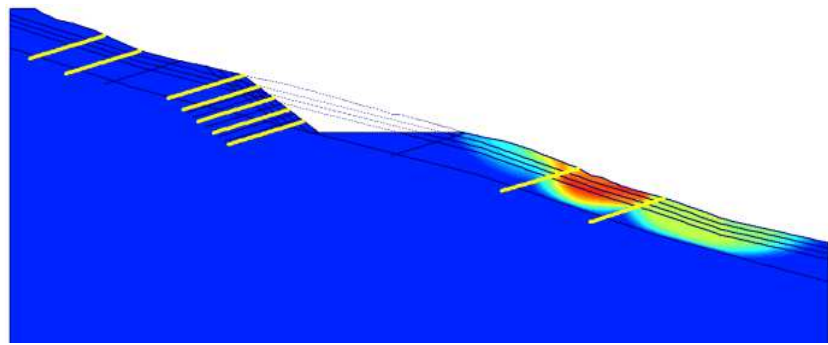

Figure 9. Model 1, Static, 10.3 m Excavation, $w=20 \%$.

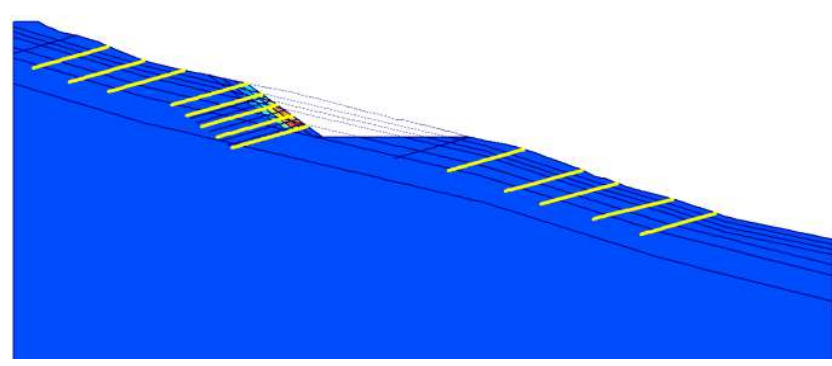

Figure 10. Model 1, Seismic, $10.3 \mathrm{~m}$ Excavation, $w=20 \%$.

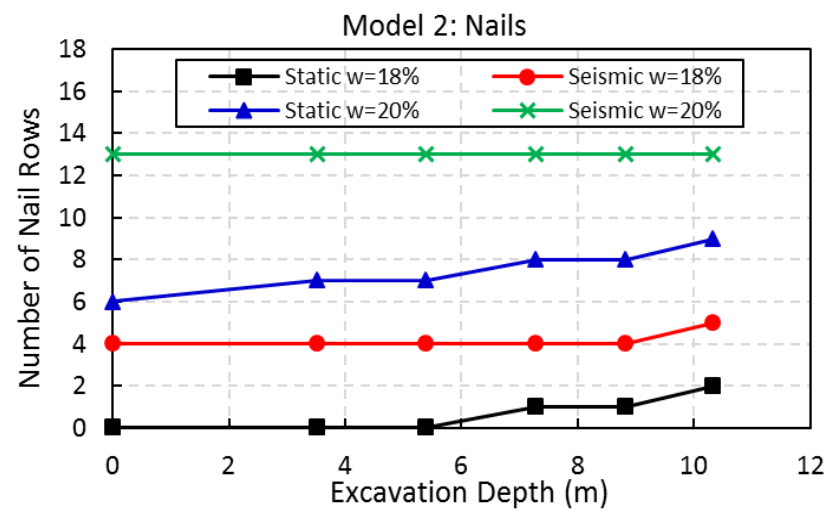

Figure 11. Model 2, Variation of Number of Nail Rows with the Variation of Excavation's Depth and Water Content.

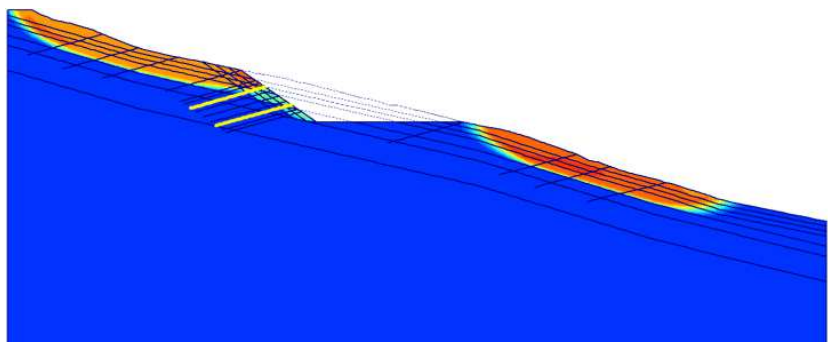

Figure 12. Model 2, Static, $10.3 \mathrm{~m}$ Excavation, $w=18 \%$.

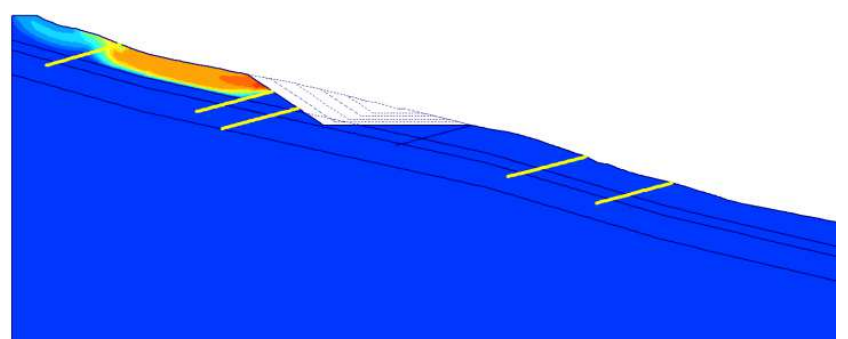

Figure 13. Model 2, Seismic, 10.3 m Excavation, $w=18 \%$.

\subsubsection{Piles}

The reinforced concrete piles used in this study are spaced of $1.8 \mathrm{~m}$ with a diameter of $60 \mathrm{~cm}$ and a length of $15 \mathrm{~m}$, a normal stiffness $\mathrm{EA}=3.14 \times 10^{6} \mathrm{kN} / \mathrm{m}$ and a flexural rigidity $\mathrm{EI}=7.07 \times 10^{4} \mathrm{kN} . \mathrm{m}^{2} / \mathrm{m}$. Figures 14 and 17 summarize the needed number of pile rows to maintain the slope stable for both models. The number of pile rows increases with the increase of both excavation's depth and water content. Figures $15,16,18$ and 19 illustrate the location of applied piles on both models.

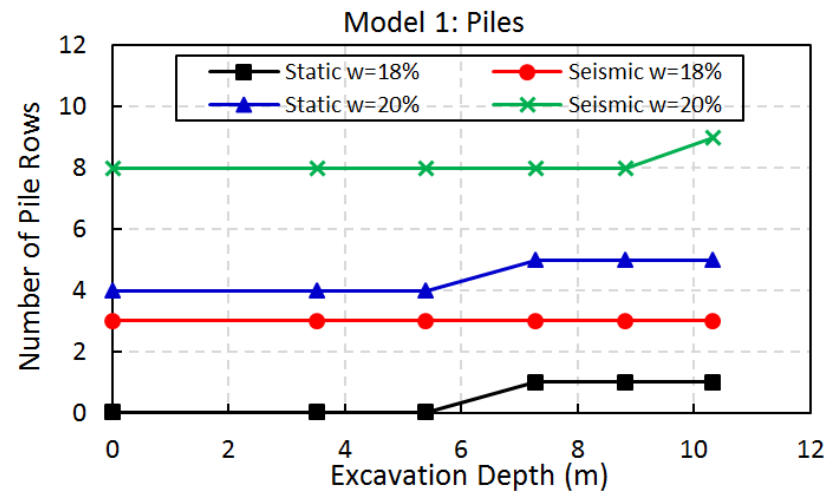

Figure 14. Model 1, Variation of Number of Pile Rows with the Variation of Excavation's Depth and Water Content.

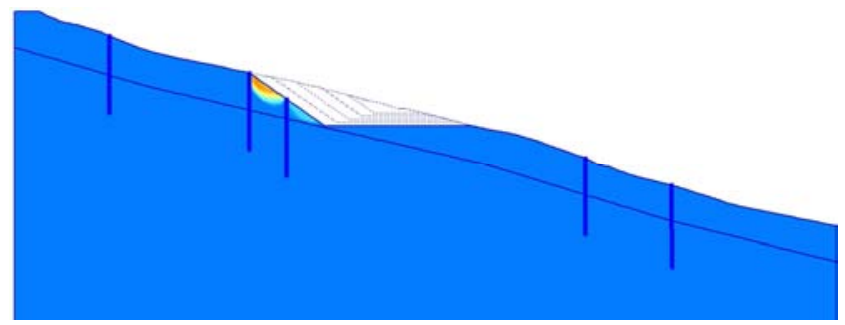

Figure 15. Model 1, Static, $10.3 \mathrm{~m}$ Excavation, $w=20 \%$. 


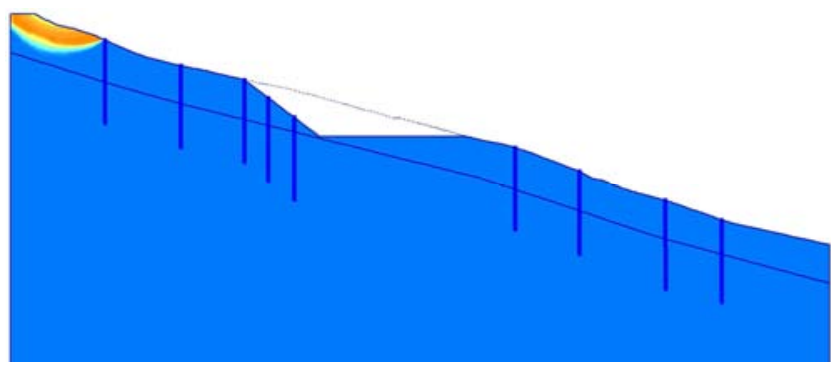

Figure 16. Model 1, Seismic, 10.3 m Excavation, $w=20 \%$.

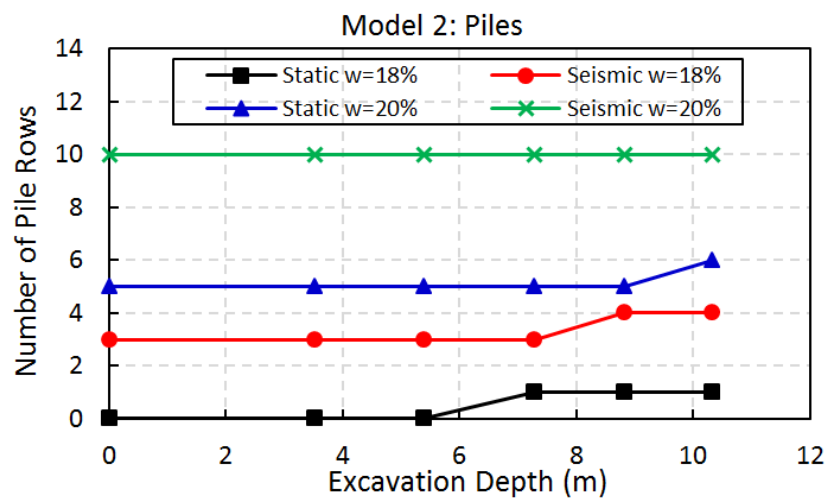

Figure 17. Model 2, Variation of Number of Pile Rows with the Variation of Excavation's Depth and Water Content.

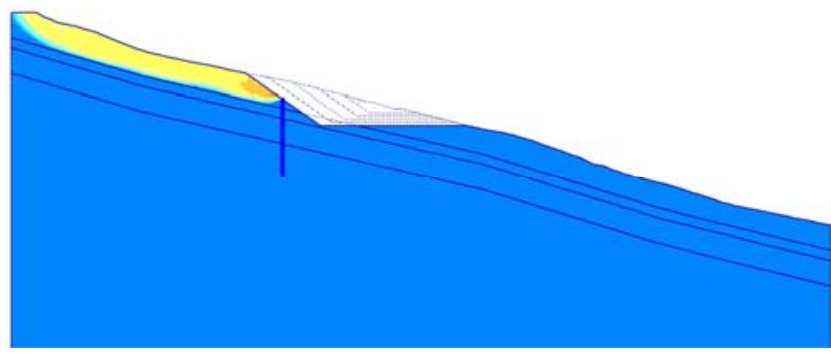

Figure 18. Model 2, Static, 10.3 m Excavation, $w=18 \%$.

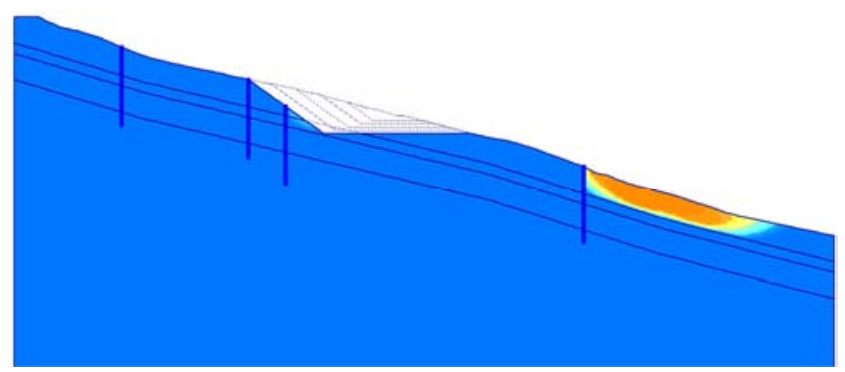

Figure 19. Model 2, Seismic, 10.3 m Excavation, $w=18 \%$.

\subsection{Vegetation}

Slope stabilization using vegetation has found wide applications since it was developed in the late of 1970's [21, 31]. Vegetation helps stabilize slopes in many ways including high biodiversity, low maintenance, self-sustainability and being environmentally-friendly [32]. Vegetation influences slope stability through hydrological and mechanical effects.

Hydrological effects involve the removal of soil water by evapotranspiration through vegetation thus reducing the soil weight, which can lead to an increase in soil suction or reduction in pore water pressure, hence an increase in the shear strength [24]. The depth of rooting affects soil moisture depletion; deep-rooted species can sustain maximum transpiration rates for greater durations, thus drying the soil at greater depths compared to shallow-rooted vegetation [33].

The shear strength of the soil is also increased through the mechanical effects of the plant root matrix system. The density of the roots within the soil mass and the root tensile strength contribute to the ability of the soils to resist shear stress. Deep tree roots penetrate into the compacted layer and tie the layers together, preventing slides [34]. In addition, roots are self-repairing, regenerating and adaptive [24].

The effects of vegetation have been incorporated in slope stability analysis by using conventional limit equilibrium method [35]. In limit equilibrium methods, the shear strength of the soil along a potential slip surface is assumed to be fully mobilized at the point of failure. The Mohr-Coulomb equation describing the shear strength:

$$
\tau=\mathrm{c}^{\prime}+(\sigma-\mathrm{u}) \tan \varphi^{\prime}
$$

By incorporating the effect of root reinforcement, the equation becomes:

$$
\tau=\left(\mathrm{c}^{\prime}+c R\right)+(\sigma-\mathrm{u}) \tan \varphi^{\prime}
$$

In this study, we have taken into account both the hydrological and the mechanical effects. The hydrological effects are considered by supposing the water content in the vegetation layer remains as the initial water content $(\mathrm{w}=15 \%)$ and does not increase in the rainfall season. Also the mechanical effects are considered by taking into account the vegetation parameters $c R$ and $h R . c R$ is the apparent soil cohesion caused by the plant root matrix system that is added to the initial cohesion. The depth of the root zone $(h R)$ is defined as the effective distance beyond which plant roots cause little or no effects on the soil shear strength.

The apparent root cohesion $(c R)$ varies over the following range:

$$
0 \leq c R \leq 20 \mathrm{kPa}
$$

Three values of depth of root zone $(h R)$ were used:

$$
h R \in\{1 \mathrm{~m}, 2 \mathrm{~m}, 3 \mathrm{~m}\}
$$

\subsubsection{Effect on Safety Factor}

By applying the vegetation layer to both models, with increasing incremental root depth $(h R)$ and cohesion $(c R)$, the safety factor increased significantly as noted in tables 7 and 8 . 
Table 7. Model 1, Percentage of Increase of Safety Factor with Vegetation

\begin{tabular}{|c|c|c|c|c|c|}
\hline \multirow{2}{*}{$\begin{array}{l}\text { Static } \\
\text { Vegetation }\end{array}$} & & \multicolumn{4}{|c|}{ Model 1 - Safety Factor } \\
\hline & & $\mathrm{w}=18 \%$ & & $\mathrm{w}=\mathbf{2 0} \%$ & \\
\hline Depth hR (m) & Cohesion cR (kPa) & \begin{tabular}{|l|} 
No Excavation \\
\end{tabular} & $10.3 \mathrm{~m}$ & No Excavation & $10.3 \mathrm{~m}$ \\
\hline \multirow[t]{2}{*}{0} & 0 & 1.589 & 1.250 & 1.151 & 0.900 \\
\hline & 0 & 1.594 & 1.261 & 1.164 & 0.910 \\
\hline \multirow[t]{3}{*}{1} & 10 & 1.600 & 1.271 & 1.176 & 0.925 \\
\hline & 20 & 1.623 & 1.293 & 1.187 & 0.931 \\
\hline & 0 & 1.607 & 1.352 & 1.193 & 1.021 \\
\hline \multirow[t]{3}{*}{2} & 10 & 1.616 & 1.413 & 1.201 & 1.052 \\
\hline & 20 & 1.630 & 1.424 & 1.207 & 1.07 \\
\hline & 0 & 1.618 & 1.441 & 1.204 & 1.088 \\
\hline \multirow[t]{2}{*}{3} & 10 & 1.633 & 1.474 & 1.223 & 1.119 \\
\hline & 20 & 1.650 & 1.501 & 1.245 & 1.158 \\
\hline Increase (\%) & & 4 & 20 & 8 & 29 \\
\hline
\end{tabular}

Table 8. Model 2, Percentage of Increase of Safety Factor with Vegetation.

\begin{tabular}{|c|c|c|c|c|c|}
\hline \multirow{2}{*}{\multicolumn{2}{|c|}{$\begin{array}{l}\text { Static } \\
\text { Vegetation }\end{array}$}} & \multicolumn{4}{|c|}{ Model 2 - Safety Factor } \\
\hline & & $\mathrm{w}=\mathbf{1 8 \%}$ & & $\mathrm{w}=\mathbf{2 0} \%$ & \\
\hline Depth hR (m) & Cohesion cR (kPa) & No Excavation & $10.3 \mathrm{~m}$ & No Excavation & $10.3 \mathrm{~m}$ \\
\hline \multirow[t]{2}{*}{0} & 0 & 1.617 & 1.194 & 1.142 & 0.978 \\
\hline & 0 & 1.633 & 1.230 & 1.194 & 1.034 \\
\hline \multirow[t]{3}{*}{1} & 10 & 1.642 & 1.248 & 1.203 & 1.042 \\
\hline & 20 & 1.657 & 1.257 & 1.212 & 1.047 \\
\hline & 0 & 1.658 & 1.356 & 1.197 & 1.088 \\
\hline \multirow[t]{3}{*}{2} & 10 & 1.648 & 1.425 & 1.212 & 1.113 \\
\hline & 20 & 1.680 & 1.484 & 1.231 & 1.141 \\
\hline & 0 & 1.679 & 1.458 & 1.213 & 1.158 \\
\hline \multirow[t]{2}{*}{3} & 10 & 1.686 & 1.519 & 1.238 & 1.215 \\
\hline & 20 & 1.692 & 1.516 & 1.262 & 1.240 \\
\hline Increase $(\%)$ & & 5 & 27 & 10.5 & 27 \\
\hline
\end{tabular}

The above tables state the visible effect of vegetation on the slope stability in the cases of $18 \%$ and $20 \%$ water content.

\subsubsection{Effect on Number of Nail Rows}

The increase in vegetation's depth and cohesion leads to the decrease in the number of nail rows needed for a stable slope in both static and seismic cases. The reduction of nail rows number varies between 40 to $100 \%$. The results of reduction percentages are summarized in table 9 and the related graphs are illustrated in figures 20 and 21 for static case.

Table 9. Percentage of Increase of Number of Nail Rows with Vegetation.

\begin{tabular}{|c|c|c|c|c|c|}
\hline \multirow{3}{*}{ Nail Rows } & & \multicolumn{4}{|c|}{ Percentage of Reduction (\%) } \\
\hline & & \multicolumn{2}{|c|}{$\mathrm{w}=18 \%$} & \multicolumn{2}{|l|}{$\mathrm{W}=\mathbf{2 0} \%$} \\
\hline & & No Excavation & $10.3 \mathrm{~m}$ & No Excavation & $10.3 \mathrm{~m}$ \\
\hline \multirow{2}{*}{ Static } & Model 1 & - & $100 \%$ & $60 \%$ & $77.8 \%$ \\
\hline & Model 2 & - & $100 \%$ & $66.7 \%$ & $77.8 \%$ \\
\hline \multirow{2}{*}{ Seismic } & Model 1 & $50 \%$ & $40 \%$ & $50 \%$ & $69.2 \%$ \\
\hline & Model 2 & $50 \%$ & $40 \%$ & $69.2 \%$ & $78 \%$ \\
\hline
\end{tabular}

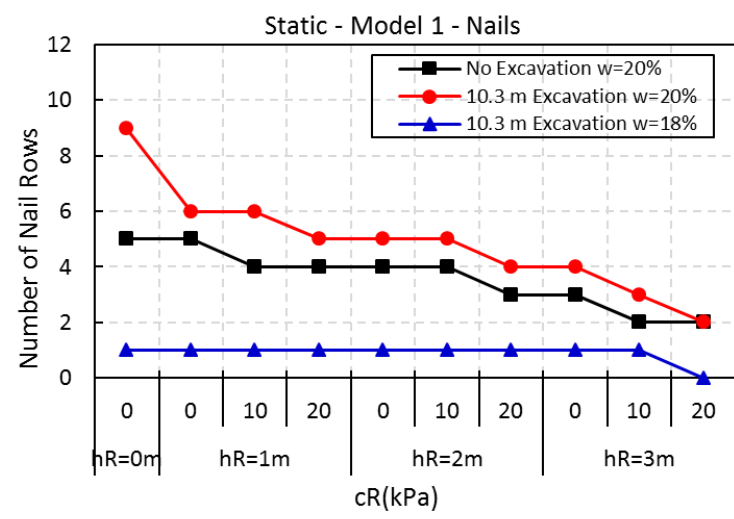

Figure 20. Model 1, Static, Variation in Number of Nail Rows.

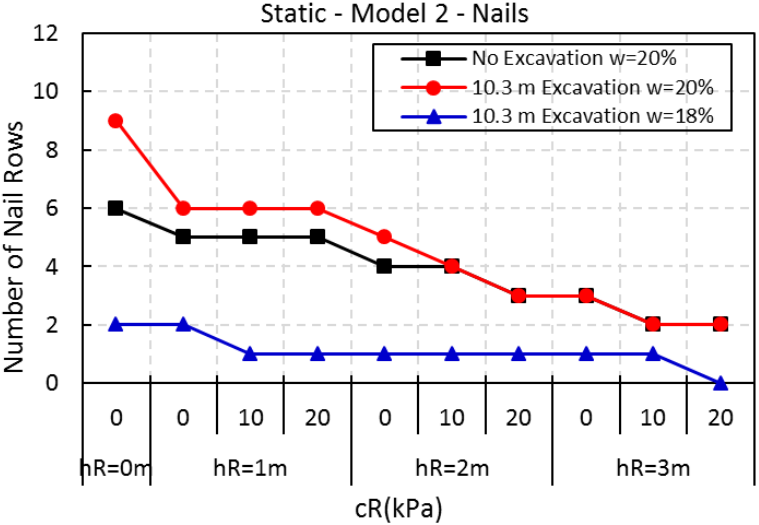

Figure 21. Model 2, Static, Variation in Number of Nail Rows. 


\subsubsection{Effect on Number of Pile Rows}

The number of pile rows needed for a stable slope in both static and seismic cases decreases also dramatically by using the vegetation; this number decreases of about 50 to $70 \%$. The results of this reduction are summarized in table 10 and illustrated in figures 22 and 23 for seismic case.

Table 10. Percentage of Increase of Number of Pile Rows with Vegetation.

\begin{tabular}{llllll}
\hline \multirow{2}{*}{ Pile Rows } & \multicolumn{4}{l}{ Percentage of Reduction (\%) } \\
\cline { 2 - 6 } & & $\mathbf{w = 1 8 \%}$ & \multicolumn{3}{l}{$\mathbf{w = 2 0 \%}$} \\
\cline { 2 - 6 } & & No Excavation & $\mathbf{1 0 . 3} \mathbf{~ m}$ & No Excavation & $\mathbf{1 0 . 3 ~ m}$ \\
\hline \multirow{2}{*}{ Static } & Model 1 & - & - & $50 \%$ & $60 \%$ \\
& Model 2 & - & $100 \%$ & $60 \%$ & $66.7 \%$ \\
\multirow{2}{*}{ Seismic } & Model 1 & $33 \%$ & $66.7 \%$ & $50 \%$ & $66.7 \%$ \\
& Model 2 & $33 \%$ & $50 \%$ & $60 \%$ & $70 \%$ \\
\hline
\end{tabular}

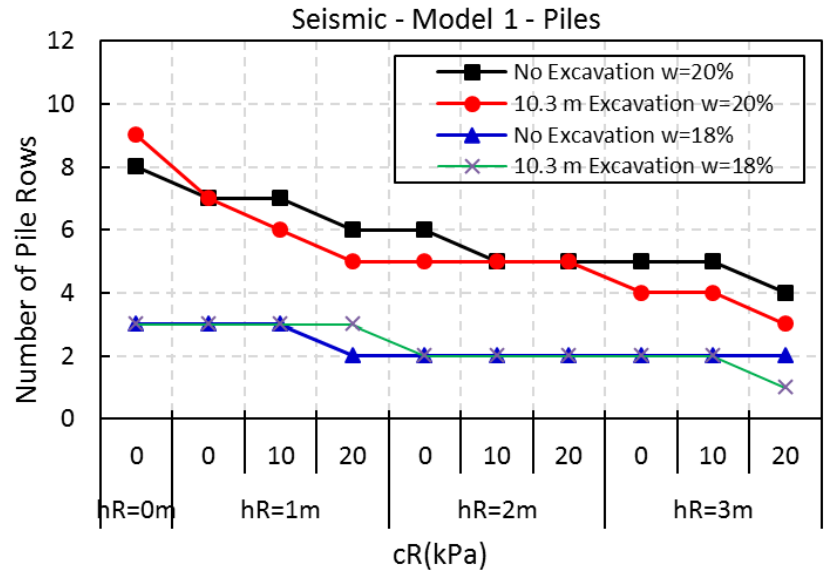

Figure 22. Model 1, Seismic, Variation in Number of Pile Rows.

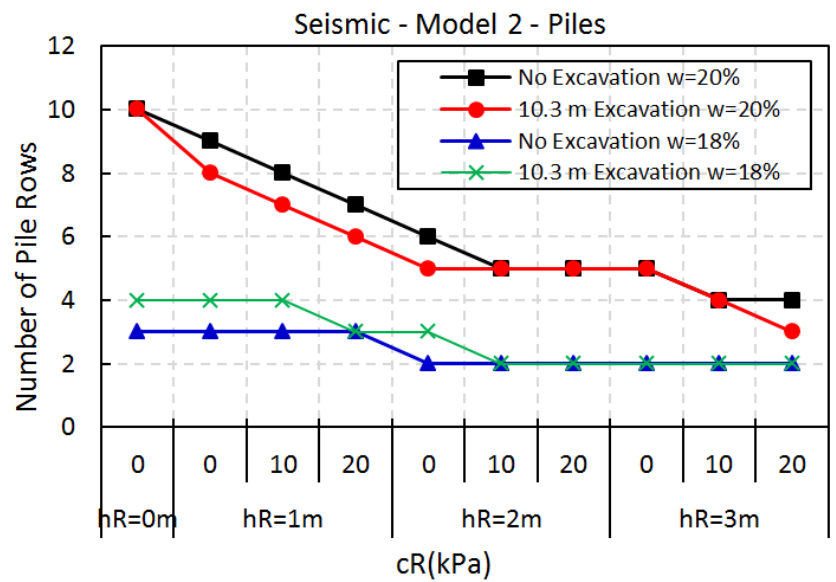

Figure 23. Model 2, Seismic, Variation in Number of Pile Rows.

\subsection{Drainage}

It is obvious that the presence of water in the slope during rainfall season contributes to slope instability. For this purpose, we studied the influence of draining trenches and sub-horizontal drains on enhancing slope stability.

First, we modeled a drainage system by a drainage trench of width of $1 \mathrm{~m}$ and a depth of 1, 2, 3, 4 and $5 \mathrm{~m}$ for both models at the top of the slope as shown in figures 24 and 25.

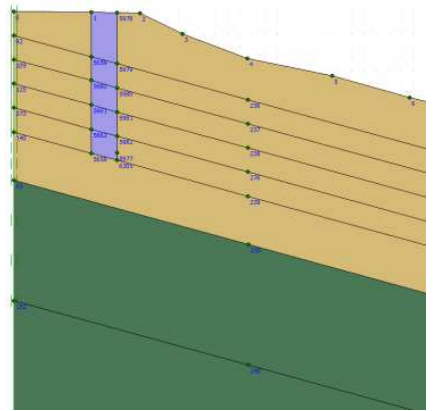

Figure 24. Model 1, Geometry of Draining Trench.

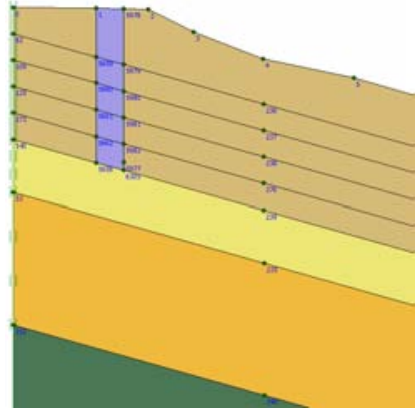

Figure 25. Model 2, Geometry of Draining Trench.

The trenches are constituted of filter materials allowing the water to be discharged through a longitudinally natural watercourse so they prevent the accumulation of water in the top layer. The cohesion of the filter materials $\mathrm{c}=1 \mathrm{kPa}$, angle of internal friction $\varphi=45^{\circ}$ and young's modulus $\mathrm{E}=80000 \mathrm{kPa}$. When applying the drainage trenches, the layer keeps its initial mechanical properties.

This partial drainage has an effect on the safety factor. It increases with the increase of the depth of the drainage trench. Tables 11 and 12 show the improvement of the safety factor with the increase of the drainage trench depth.

Table 11. Model 1, Variation of SF with Increasing Drainage Trench Depth.

\begin{tabular}{lllll}
\hline Static & \multicolumn{4}{l}{ Model 1 - Safety Factor } \\
\hline Drainage Trench & w=18\% & & w=20\% & \\
\hline Depth (m) & No Excavation & $\mathbf{1 0 . 3} \mathbf{~ m}$ & No Excavation & $\mathbf{1 0 . 3} \mathbf{~ m}$ \\
\hline 0 & 1.559 & 1.213 & 1.138 & 0.89 \\
1 & 1.576 & 1.213 & 1.144 & 0.89 \\
2 & 1.583 & 1.213 & 1.163 & 0.94 \\
3 & 1.591 & 1.242 & 1.182 & 1.01 \\
4 & 1.624 & 1.303 & 1.223 & 1.08 \\
5 & 1.645 & 1.378 & 1.261 & 1.19 \\
Increase (\%) & 5.5 & 13.6 & 10.8 & 33.7 \\
\hline
\end{tabular}

Table 12. Model 2, Variation of SF with Increasing Drainage Trench Depth.

\begin{tabular}{lllll}
\hline Static & Model 2 - Safety Factor & & \\
\hline Drainage Trench & w=18\% & & w=20\% & \\
\hline Depth (m) & No Excavation & $\mathbf{1 0 . 3} \mathbf{~ m}$ & No Excavation & $\mathbf{1 0 . 3} \mathbf{~ m}$ \\
\hline 0 & 1.552 & 1.194 & 1.103 & 0.940 \\
1 & 1.600 & 1.194 & 1.135 & 0.940 \\
2 & 1.640 & 1.198 & 1.166 & 0.952 \\
3 & 1.680 & 1.238 & 1.188 & 1.026 \\
4 & 1.770 & 1.320 & 1.229 & 1.082 \\
5 & 2.293 & 1.440 & 2.293 & 1.440 \\
Increase (\%) & 47.7 & 20.6 & 108 & 53.2 \\
\hline
\end{tabular}


Since we have a noticeable increase in the safety factor, then this partial drainage definitely has an effect on the soil reinforcements, number of nail rows and pile rows. Table 13 shows the reduction percentage of number of nail and pile rows after the application of the partial drainage to obtain a stable slope. Figures 26 and 27 show the variation of number of nail rows due to partial drainage of model 1 .

Table 13. Reduction Percentage of Number of Nail and Pile Rows After Application of Partial Drainage.

\begin{tabular}{|c|c|c|c|c|c|c|}
\hline & & \multirow{3}{*}{ Models } & \multicolumn{4}{|c|}{ Percentage of Reduction (\%) } \\
\hline & & & \multicolumn{2}{|l|}{$w=18 \%$} & \multicolumn{2}{|l|}{$\mathrm{w}=\mathbf{2 0} \%$} \\
\hline & & & No Excavation & $10.3 \mathrm{~m}$ & No Excavation & $10.3 \mathrm{~m}$ \\
\hline \multirow{4}{*}{ Nail rows } & \multirow{2}{*}{ Static } & 1 & - & - & $60 \%$ & $55.5 \%$ \\
\hline & & 2 & - & $50 \%$ & $100 \%$ & $90 \%$ \\
\hline & \multirow{2}{*}{ Seismic } & 1 & $50 \%$ & $60 \%$ & $58.5 \%$ & $61.5 \%$ \\
\hline & & 2 & $100 \%$ & $80 \%$ & $100 \%$ & $92.3 \%$ \\
\hline \multirow{3}{*}{ Pile rows } & Static & 2 & - & $50 \%$ & $100 \%$ & $83.3 \%$ \\
\hline & \multirow{2}{*}{ Seismic } & 1 & $33.3 \%$ & $33.3 \%$ & $50 \%$ & $55.5 \%$ \\
\hline & & 2 & $100 \%$ & $75 \%$ & $100 \%$ & $90 \%$ \\
\hline
\end{tabular}

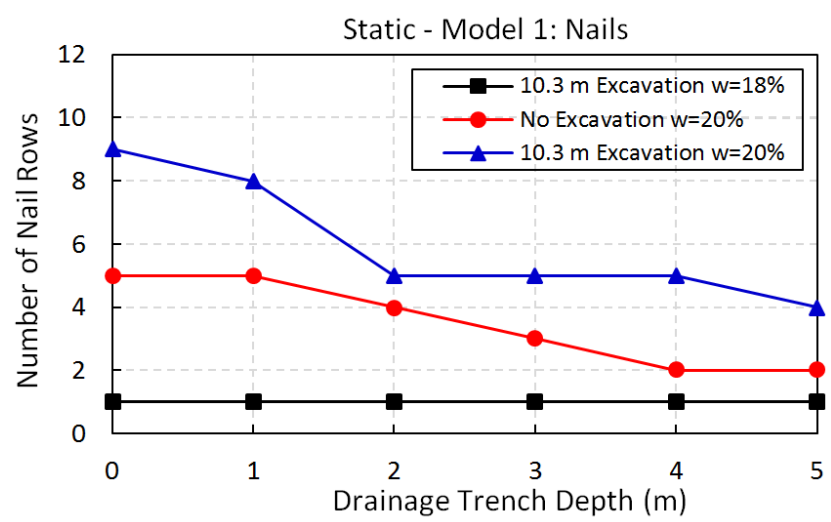

Figure 26. Model 1, Static, Variation of Number of Nail Rows Due to Partial Drainage.

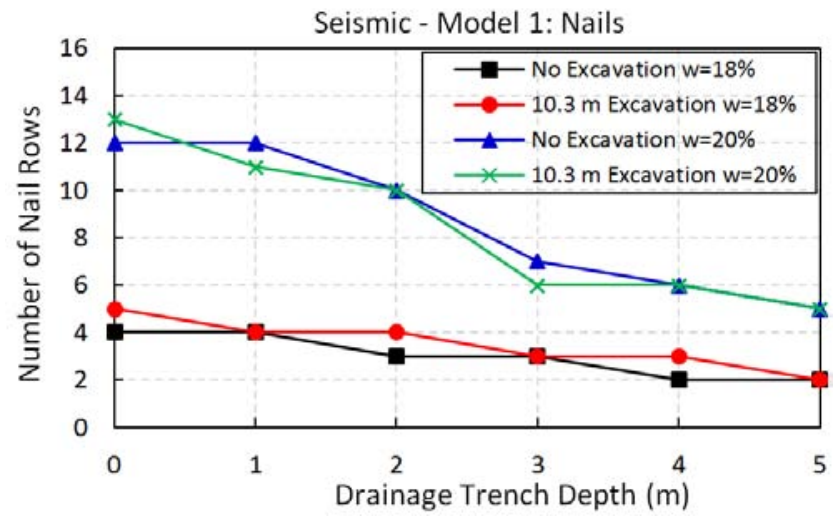

Figure 27. Model 1, Seismic, Variation of Number of Nail Rows Due to Partial Drainage.

Another drainage method is the sub-horizontal drains where the slope becomes completely drained. Fully drained slope takes it back to its initial condition where water content remains $15 \%$ and its mechanical properties remain the same. In this case, the slope is stable for both models in static and seismic cases even without the disposition of any kind of reinforcement, except for the $10.3 \mathrm{~m}$ excavation's depth in the second model where only one row of nails or piles is needed to reach stability in static and seismic cases.

\section{Conclusion}

In this paper, we studied the stability of a slope located in Lebanon subjected to failure during the rainfall season. The mechanical characteristics of soil were taken from boreholes results for the same site, where two models are simulated using Plaxis and Talren softwares.

Initially, the slope in both models was stable even after the application of an excavation and seismic load. The slope was studied under the effect of water where it was clear that water is a principle cause of slope instability. Water caused failure either by decreasing the shear parameters of the top layers or by the inducing pore pressure due to running water between layers.

Finding the most adequate remedy requires a perfect knowledge of the cause of the instability. First, we used soil reinforcements, nails and piles, and the results showed that the increase of the water content requires a large number of piles and nails to ensure the slope stability. The results show that piles and nails are adequate but maybe expensive remedies and they do not attack the cause of sliding but are intended to reduce or stop the deformations.

To overcome the cause of sliding which is water, vegetation and drainage were proposed and modeled. First, vegetation, which is a less expensive and an environmental friendly remedy that has hydrological and mechanical effects, was studied and modeled. As the root cohesion and depth increases, the safety factor increases and the needed number of nail and pile rows decreases dramatically. Moreover, the draining trenches and sub-horizontal drainage were tested. The draining trenches were modeled for different depths at the top of the slope, and the results showed that as the depth increases, the safety factor increases and the needed number of nail and pile rows decreases. In parallel, the application of sub-horizontal drainage has demonstrated that the slope becomes fully drained and it goes back to its initial stable state. 


\section{Acknowledgements}

We express our acknowledgement to the National Council for Scientific Research in Lebanon (CNRSL) for his financial support for this research.

\section{References}

[1] M. R. Taha, M. Khajehzadeh and A. El-Shafie, "Slope Stability Assessment Using Optimization Techniques: An Overview", Electronic Journal of Geotechnical Engineering, vol. 15, pp. 1901-1915, 2010.

[2] W. Fellenius, "Erdstatische Berechnungen Mit Reibung Und Kohaesion”, Berlin, Ernst, 1927.

[3] N. Janbu, "Stability analysis of slopes with dimensionless parameters", Harvard Soil Mechanics Series, 46, 811, 1954.

[4] A. W. Bishop, "The Use of the Slip Circle in the Stability Analysis of Slopes", Géotechnique, vol. 5, issue 1, pp. 7-17, 1955.

[5] N. R. Morgenstern and V. E. Price, "The analysis of the stability of general slip surfaces", Géotechnique, vol. 15, issue 1, pp. 79-93, 1965.

[6] E. Spencer, "A method for analysis of the stability of embankments assuming parallel interslice forces", Géotechnique, vol. 17, issue 1, pp. 11-26, 1967.

[7] A. Kourdey, M. Aiheib and J. P. Piguet, "Evaluation of Slope Stability by Numerical Methods", Proceedings of the $17^{\text {th }}$ International Mining Congress and Exhibition of Turkey, pp. 705-710, 2001.

[8] N. Farshidfar and A. Nayeri, "Slope Stability Analysis by Shear Strength Reduction Method", Journal of Civil Engineering and Urbanism, vol. 5, issue 1, pp. 35-37, 2015.

[9] M. Cala, J. Flisiak and A. Tajdus, "Slope Stability Analysis with Modified Shear Strength Reduction Technique", Landslides: Evaluation and Stabilization, pp. 1085-1089, 2004.

[10] K. Baba, L. Bahi, L. Ouadif and A. Akhssas, "Slope Stability Evaluations by Limit Equilibrium and Finite Element Methods Applied to a Railway in the Moroccan Rif', Open Journal of Civil Engineering, pp. 27-32, 2012.

[11] G. A. Fenton, and E. H. Vanmarcke, "Simulation of random fields via local average subdivision". Journal of Engineering Mechanics, vol. 116, issue 8, pp. 1733-1749, 1990.

[12] D. V. Griffiths and G. A. Fenton, "Probabilistic Slope Stability Analysis by Finite Elements", Journal of Geotechnical and Geoenvironmental Engineering, vol. 130, issue 5, pp. 507-518, 2004.

[13] Y. S. Song, W. P. Hong and K. S. Woo, "Behavior and Analysis of Stabilizing Piles Installed in a Cut Slope during Rainfall", Engineering Geology, vol. 129, pp. 56-67, 2012.

[14] W. B. Wei and Y. M. Cheng, "Strength Reduction Analysis for Slope Reinforced with one Row of Piles", Computers and Geotechnics, vol. 36, pp. 1176-1185, 2009.

[15] R. Kourkoulis, F. Gelagoti, I. Anastasopoulos and G. Gazetas, "Slope Stabilizing Piles and Pile-Groups: Parametric Study and Design Insights", Journal of Geotechnical and Geoenvironmental
Engineering, vol. 137, issue 7, pp. 663-677, 2011.

[16] S. He, C. Ouyang and Y. Luo, "Seismic Stability Analysis of Soil Nail Reinforced Slope using Kinematic Approach of Limit Analysis", Environmental Earth Sciences, vol. 66, issue 1, pp. 319-326, 2012.

[17] C. Fan and J. Luo, "Numerical Study on the Optimum Layout of Soil-Nailed Slope", Computers and Geotechnics, vol. 35, pp. 585-599, 2008.

[18] G. Carter, "La stabilisation des Pentes Instables par Clouage. Bulletin liaison des Ponts et Chaussées", vol. 141, 1986, pp. 45-56, 1986.

[19] P. Valli, "Numerical Study to Stabilize Landslides by Trench Drains", Computers and Geotechnics, vol. 27, pp. 63-77, 2000.

[20] F. Cai, K. Ugai, A. Wakai and Q. Li, "Effects of Horizontal Drains on Slope Stability Under Rainfall by Three-Dimensional Finite Element Analysis", Computers and Geotechnics, vol. 23, pp. 255-275, 1998.

[21] D. H. Barker. "Continuing and Future Developments in Vegetative Slope Engineering or Ecoengineering". Proceedings of the International Conference on Vegetation and Slopes, Oxford, pp. 29-30, 1994.

[22] J. R. Greenwood, J. E. Norris, and J. Wint, "Assessing the contribution of vegetation to slope stability, Proceedings of the ICE-Geotechnical Engineering”, vol. 157, issue 4, pp. 199-207, 2004.

[23] A. Stokes, C. Atger, A. G. Bengough, T. Fourcaud, R. C. Sidle, "Desirable plant root traits for protecting natural and engineered slopes against landslides", Plant Soil, vol. 324, issue 1-2, pp. 1-30, 2009.

[24] N. Ali, I. Farshchi, M. A. Mu'azu, and S. W. Rees, "Soil-Root Interaction and Effects on Slope Stability Analysis", Electronic Journal of Geotechnical Engineering, vol 17, pp. 319-328, 2012.

[25] S. Hemmati, and A. Modaressi, "Étude de la stabilité des pentes non saturées sous les effets de l'infiltration prenant en compte la végétation", Proceedings of the $18^{\text {th }}$ International Conference on Soil Mechanics and Geotechnical Engineering, Paris, pp. 1117-1121, 2013.

[26] M. Charlafti, "Slope stability and vegetation", J Archit Eng Tech, vol. 3, issue 4, 2014.

[27] L. C. Wang, W. Long, S. J. Gao, "Effect of moisture content, void ratio and compacted sand content on the shear strength of remolded unsaturated clay", Electronic Journal of Geotechnical Engineering, vol. 19, pp. 4413-4426, 2014.

[28] K. Blahova, L. Ševelova and P. Pilařova, "Influence of Water Content on The Shear Strength Parameters of Clayey Soil in Relation to Stability Analysis of a Hillside in BRNO Region", Acta Univ. Agric. Silvic. Mendelianae Brun., vol. 61, pp. 1583-1588, 2013.

[29] M. A. Dafalla, "Effects of Clay and Moisture Content on Direct Shear Tests for Clay-Sand Mixtures", Hindawi Publishing Corporation, Advances in Materials Science and Engineering, 2013.

[30] N. A. Al-Shayea, "The combined effect of clay and moisture content on the behavior of remolded unsaturated soils", Engineering Geology vol. 62, pp. 319-342, 2001. 
[31] K. Wang, C. F. Lee, "Brief Mechanical Analysis of Bioengineering Techniques for Slope Protection", Chinese Journal of Rock Mechanics and Engineering, vol. 17, issue 6, pp. 687-691, 1998.

[32] O. Normaniza and S. S. Barakbah. "Parameter to Predict Slope-Soil Water and Root Profiles", Ecological Engineering, vol. 28, Issue 1, pp. 90-95, 2006.

[33] K. G. McNaughton, and P. G. Jarvis, "Predicting Effects of Vegetation Changes on Transpiration and Evaporation", Water Deficits and Plant Growth, vol. 7, pp. 1-47, 1983.
[34] Y. H. Chok, W. S. Kaggwa, M. B. Jaksa, and D. V. Griffiths, "Modelling the effects of vegetation on stability of slopes", Proceedings of the $9^{\text {th }}$ Australia New Zealand conference on geomechanics, Auckland, pp. 391-397, 2004.

[35] T. H. Wu, W. P. Mc Kinnell III, and D. N. Swanston, "Strength of tree roots and landslides on Prince of Wales Island, Alaska", Canadian Geotechnical Journal, vol. 114, issue 12, pp. 19-33, 1979. 